\title{
Sandwich materials with a crumpled aluminium core
}

\author{
Olivier Bouaziz ${ }^{1,2,{ }^{*}}$, Rabeb Bouafif ${ }^{1,2}$, and Roxanne Massion ${ }^{1,2}$ \\ ${ }^{1}$ Laboratoire d'Étude des Microstructures et de Mécanique des Matériaux (LEM3), CNRS, Université de Lorraine, Arts et \\ Métier Paris Tech, 57000 Metz, France \\ ${ }^{2}$ LABoratoire d'EXcellence DAMAS, Université de Lorraine, 57000 Metz, France
}

Received: 25 December 2020 / Accepted: 12 February 2021

\begin{abstract}
Sandwich materials made of two aluminum sheets and a crumpled aluminum core have been manufactured for the first time using a reproducible process. This very specific core aims to drastically improve the elasticity performance indexes of the sandwich. The structure has been studied mainly in bending.
\end{abstract}

Keywords: sandwich / crumpled / aluminium / stiffness / bending

\section{Introduction}

Sandwich solution with light core is a well known strategy to improve the stiffness as a function of density [1-4]. That is the reason why the using of metallic foams as a core has been widely investigated (see [5] for a review). More recently the behaviour of crumpled aluminium thin foils in close die compression and in uniaxial compression has been carried out [6,7]. These structures are composed of two sheets of a rigid material between which is placed a material often lighter (the core). These sandwiches often have a good flexural strength/density and also have other functional properties, such as thermal or acoustic insulation. The strategy of developing sandwich structures gives considerable degrees of freedom: choice of core and sheet materials, geometry... but also requires the development of a specific characterization and design methodology. The conclusion is the following: the crumpled samples exhibit competitive specific stiffness (stiffness as function of density) compared with available metallic foams with a strong decrease in the cost. Consequently an opportunity to develop sandwich materials with crumpled thin foils core appears. So this publication reports for the first time the manufacture of such sandwiches solutions and the characterization by the bending test in order to measure the specific stiffness.

\section{Manufacture}

The first step in sandwich manufacturing is the compaction of the crumpled aluminum core in two steps. This operation starts with a manual crumpling of food-grade aluminum

\footnotetext{
* e-mail: olivier.bouaziz@univ-lorraine.fr
}

foil (thickness $=20 \mu \mathrm{m}$ ) and is followed by controlled compaction in a specially designed channel-die type matrix. As illustrated in Figure 1, the specific device has been machined including a T-shape punch and a U-shape die suitable to the forming of core. The die is partially fill up with crumpled thin foils and the forming of a flat core, thin foils are compacted on a conventional compression machine. Knowing the initial quantity of matter included in the die, the final displacement of the punch provides the final density of the core. An example of flat core is illustrated in Figure 2. The size of core is respectively $100 \mathrm{~mm}$ length and $10 \mathrm{~mm}$ width.

To finalize the preparation of the sandwich, the crumpled $\mathrm{Al}$ core is glued between two industrial aluminum plates, as shown in Figure 3 and as reported in [8], dimension $100 \mathrm{~mm}$ by $10 \mathrm{~mm}$ and $1 \mathrm{~mm}$. Figure 3 shows a sandwich in its final state ready to be mechanically characterized. The adhesive layer is thin and does not affect the overall resistivity of the assembly.

\section{Mechanical characterization}

The aim is to develop light structure with a high stiffness in bending per unit mass. The geometrical factors are summarized in Figure 4. Therefore three points bending have been performed as illustrated in Figure 5. Three samples with different thicknesses and different densities of the core have been investigated as reported in Table 1 . The force as a function of the displacement is plotted in Figure 6 . The average linear slope has been also measured and reported in Table 1.

This part is dedicated to compute the rigidity from the properties and the geometries (Fig. 5) of the core (crumpled aluminium) and the skins (aluminium). In three point 

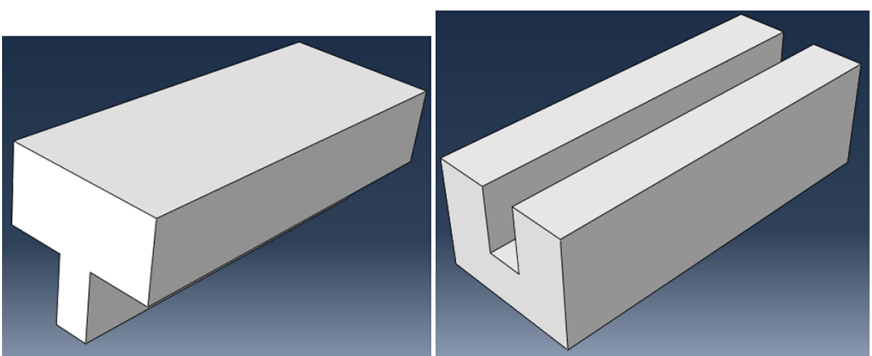

Fig. 1. Sketch of the punch and of the die for forming of the core.

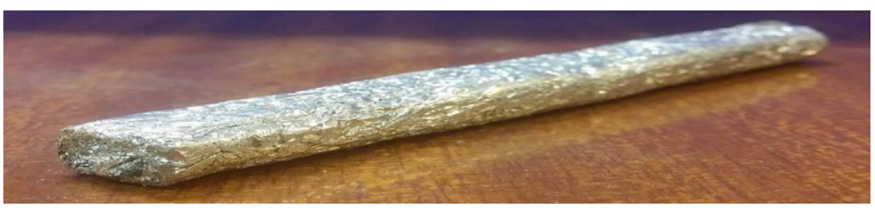

Fig. 2. Photography of a typical flat core.

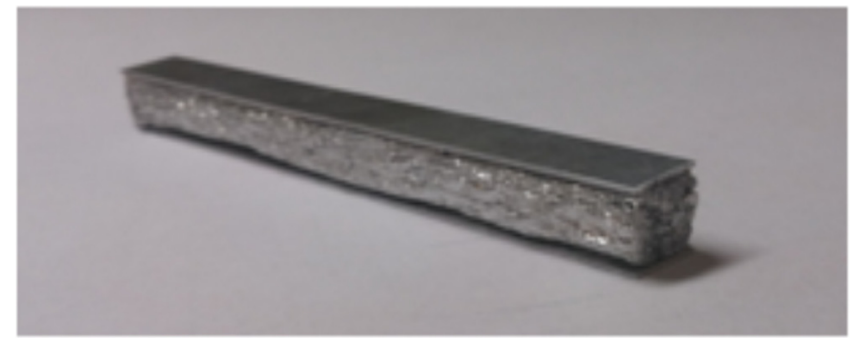

Fig. 3. Principle of manufacture of sandwich material with crumpled core.

bending, the relation between the displacement and the force is expressed as:

$$
d=\frac{F \cdot L^{3}}{48 \cdot\langle E I\rangle_{e q}},
$$

as $E_{s}$ and $E_{c}$ are respectively the Young modulus of the skins and of the core where $E_{c}<<E_{s}$ and $t<<e$ we have [9]:

$$
\langle E I\rangle_{e q}=\frac{E_{s} \cdot b \cdot t \cdot e^{2}}{2}+\frac{E_{s} \cdot b \cdot t^{3}}{6}+\frac{E_{c} \cdot b \cdot c^{3}}{12} \cong \frac{E_{s} \cdot b \cdot t \cdot e^{2}}{2} .
$$

Finally, it comes from equations (1) and (2):

$$
\frac{F}{d}=24 \cdot \frac{E_{s} \cdot b \cdot t \cdot e^{2}}{L^{3}},
$$

with $E_{s}$ is equal to $70 \mathrm{GPa}$.

This theoretical expression has been computed and is reported in Table 1. The value is about two times higher that the measured stiffness. It is assumed that this discrepancy is due to the glued interface.

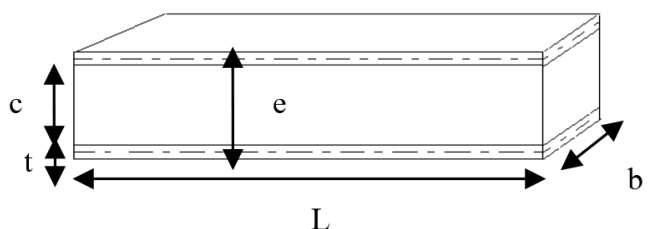

Fig. 4. Geometrical factors of sandwich.

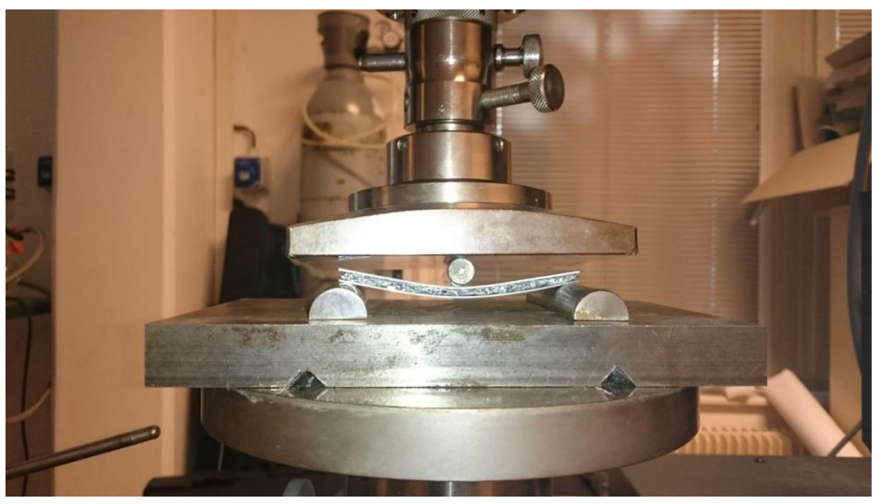

Fig. 5. Device used for the three points bending mechanical testing.

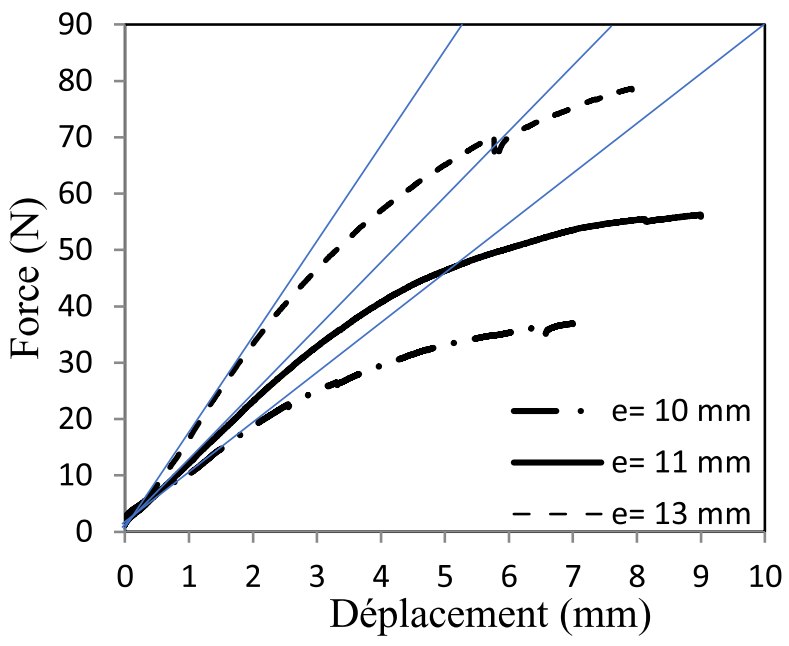

Fig. 6. Force as a function of the displacement in three points bending for each investigated sample and the average slope of the linear portion of the curves. 
Table 1. Summary of the characteristics of the investigated samples.

\begin{tabular}{|c|c|c|c|c|c|c|c|}
\hline Sample & $\begin{array}{l}\text { Thickness } \\
(\mathrm{mm})\end{array}$ & $\begin{array}{l}\text { Mass } \\
(\mathrm{kg})\end{array}$ & $\begin{array}{l}\rho_{c} \\
\left(\mathrm{~kg} / \mathrm{m}^{3}\right)\end{array}$ & $\begin{array}{l}\rho \\
\left(\mathrm{kg} / \mathrm{m}^{3}\right)\end{array}$ & $\begin{array}{l}\text { The relative density } \frac{\rho_{c}}{\rho_{A l}} \\
(\%)\end{array}$ & $\begin{array}{l}\text { Measured stiffness } \\
\mathrm{F} / \mathrm{d}(\mathrm{N} / \mathrm{mm})\end{array}$ & $\begin{array}{l}\text { Theoretical stiffness } \\
\mathrm{F} / \mathrm{d}(\mathrm{N} / \mathrm{mm}) \\
\text { Equation }(3)\end{array}$ \\
\hline 1 & 10 & $2.08 \times 10^{-3}$ & 260 & 748 & 9.6 & 9 & 16.8 \\
\hline 2 & 11 & $2.95 \times 10^{-3}$ & 328 & 491 & 12.14 & 12 & 20.3 \\
\hline 3 & 13 & $4.07 \times 10^{-3}$ & 370 & 415 & 13.70 & 17.3 & 28.4 \\
\hline
\end{tabular}

\section{Conclusion}

Due to the promising specific properties (properties per unit mass) of crumpled aluminium thin foil, sandwiches with such a core material have been manufactured for the first time. The three point bending stiffness for different conditions has been investigated. The stiffness as a function of the density is good but compared to the theoretical stiffness, the measured rigidity is lower. It has been assumed that it is due of the assembly between the skins and the core using glue. Other assembly methods should be tried as welding for optimization and lightening purposes.

\section{References}

1. M.F. Ashby, Y.J.M. Bréchet, Designing hybrid materials, Acta Mat. 51, 5801-5821 (2003)

2. D. Zenkert (ed.), The handbook of sandwich construction, North European Engineering and Science Conference Series, 1997
3. H.G. Allen, Analysis and design of structural sandwich panels, Pergamon Press, Oxford, UK, 1969

4. M. Ashby, Materials Engineering Science Processing and Design, 1st ed., 2007

5. M.F. Ashby, A.G. Evans, N.A. Fleck, L.J. Gibson, J.W. Hutchinson, H.N.G. Wadley, Metal foams: A design guide, Butterworth Heinemann, Boston, 2000

6. O. Bouaziz, J.P. Masse, S. Allain, L. Orgéas, P. Latil, Compression of crumpled aluminum thin foils and comparison with other cellular materials, Mat. Sci. Eng. A 570, 1-7 (2013)

7. S. Cottrino, P. Viviès, D. Fabrègue, E. Maire, Mechanical properties of crumpled aluminium foils, Acta Mat. 81, 98-110 (2014)

8. A.J. Kinlloch, Adhesion and adhesive, Science and Technology Chapman and Hall, London, New York, 1987

9. S. Samlal, R. Santhanakrishnan, V. Paulson, C. Goyal, Flexural property evaluation of foam core sandwich panel with carbon/kevlar epoxy hybrid face sheets, Mater. Today: Proc., in press

Cite this article as: Olivier Bouaziz, Rabeb Bouafif, Roxanne Massion, Sandwich materials with a crumpled aluminium core, Metall. Res. Technol. 118, 320 (2021) 